\title{
Effects of propofol on LC3II and mTOR/p-mTOR expression during ischemia-reperfusion myocardium injury in rats with type 2 diabetes mellitus
}

\author{
YING WANG $^{1}$, KECHENG ZHANG $^{2}$, XIURU QI $^{2}$, GUANG YANG $^{1}$, \\ HONGJIE WANG $^{2}$, ZHE ZHANG ${ }^{3}$ and BAOFENG YANG ${ }^{4}$ \\ ${ }^{1}$ Department of Anesthesiology, Affiliated Hospital of Hebei University; ${ }^{2}$ Department of Medicine, Hebei University,
Baoding, Hebei 071000; ${ }^{3}$ Hebei Medical Science and Technology Development Research Center, Shijiazhuang,
Hebei 051000; ${ }^{4}$ Health and Family Planning Commission of Hebei, Shijiazhuang, Hebei 050000, P.R. China
}

Received February 13, 2019; Accepted November 5, 2019

DOI: $10.3892 /$ etm.2020.8499

\begin{abstract}
To investigate the effects of propofol on myocardial ischemia reperfusion in rats with type 2 diabetes, male adult rats were divided into five groups: Sham-operation (CC), ischemia-reperfusion (CI), low-dose propofol (LP), moderate-dose propofol (MP) and high-dose propofol (HP). The LP, MP and HP groups were administered with 6,12 and $24 \mathrm{mg} / \mathrm{kg} / \mathrm{h}$ propofol, respectively, prior to occlusion. Heart rate (HR), left ventricular systolic pressure (LVSP) and the rate (dp/dt max) of left ventricular pressure rise in early systole $( \pm \mathrm{dp} / \mathrm{dt}$ max) were recorded. The role of autophagy was also studied by measuring the levels of superoxide dismutase (SOD), malondialdehyde (MDA), autophagy marker protein LC3II, mammalian target of rapamycin (mTOR)/phosphorylate (p)-mTOR and cardiac troponin $\mathrm{T}$ (cTnT). The myocardial morphological features were assessed using light and electron microscopy. The present results demonstrated that the HR, LVSP, +dp/dt and -dp/dt levels in the propofol groups (LP, MP and HP) were significantly increased $(\mathrm{P}<0.05)$ when compared with the CI group. The myocardial cells in the MP group showed mild edematous changes and partially dissolved mitochondrial cristae and membrane rupture. SOD, cTnT and MDA levels were significantly decreased $(\mathrm{P}<0.05)$, mTOR expression decreased significantly $(\mathrm{P}<0.05)$ and $\mathrm{p}-\mathrm{mTOR}$ expression increased significantly in the MP group $(\mathrm{P}<0.05)$. The present study demonstrated the protective effects of propofol in T2DM rats exhibiting MIRI, with an optimal protective effect at an
\end{abstract}

Correspondence to: Professor Hongjie Wang, Department of Medicine, Hebei University, 342 East Yuhua Road, Baoding, Hebei 071000, P.R. China

E-mail: hongjiew68@163.com

Key words: propofol, diabetes mellitus, myocardial ischemia reperfusion, autophagy, cardiac troponin $\mathrm{T}$, superoxide dismutase, malondialdehyde, LC3II, mechanistic target of rapamycin, phosphomechanistic target of rapamycin infusion rate of $12 \mathrm{mg} / \mathrm{kg} / \mathrm{h}$. Additionally, the results revealed that propofol led to significant reductions in LC3II and mTOR serum levels and the inhibition of autophagy in myocardial cells.

\section{Introduction}

The incidence of type 2 diabetes (T2DM) continues to increase yearly $(1,2)$. Patients with T2DM are 2-4 times higher than non-diabetics due to coronary heart disease (CHD) (3). Type 2 diabetes mellitus and coronary heart disease are common diseases. A growing number of patients with diabetes mellitus and heart disease require surgery. Due to recent advances in medical technology, the number of patients with T2DM that is complicated with CHD, who also undergo surgery, has increased (4). The selection and application of perioperative anesthetic drugs in patients with T2DM is important.

A previous study in rats demonstrated that autophagy is closely associated with T2DM $(5,6)$ and myocardial ischemia reperfusion injury (MIRI) (7). Mammalian target of rapamycin (mTOR) is a key regulator of cell growth, autophagy, translation and survival (8). The phosphorylated (p)-mTOR/mTOR signaling pathway serves a role in a variety of cell autophagy processes (9). LC3II is an autophagy-related factor, is the most widely studied family protein, is associated with autophagosome development and maturation and is used to monitor autophagic activity (10). The selection and application of perioperative anesthetic drugs in patients with T2DM that is complicated with coronary heart disease, is becoming increasingly important. Propofol, a widely used intravenous anesthetic, is reported to exhibit myocardial protective effects (11). There have been a number of reports regarding the effect of propofol on myocardial ischemia-reperfusion injury (12-14). However, the effect of propofol on diabetes mellitus with myocardial ischemia-reperfusion injury has not yet been reported. The underlying mechanism of this interaction is yet to be determined. The effects of propofol on LC3II, mTOR and p-mTOR expression in diabetic rats with MIRI has, to the best of our knowledge, not yet been investigated. In the current study, the effects of propofol on myocardial ischemia 
reperfusion in rats with $\mathrm{T} 2 \mathrm{DM}$ is investigated. The present study also investigated whether LC3II, mTOR and p-mTOR serve roles in T2DM rats with MIRI, and investigated the role that autophagy serves in this process.

\section{Materials and methods}

Preparation of experimental rats. The current study has been examined by the Animal Welfare and Ethical Committee of Hebei University. A total of 50 healthy Sprague-Dawley male rats (age, 6-8 weeks; weight, 200-220 g) were provided by Hebei Experimental Animal Center [certificate no. SSCXK (Ji) 2013-1-1003]. Rats were randomly divided into five groups, with 10 rats in each group. The groups were as follows: Sham-operation (group CC), ischemia-reperfusion (group $\mathrm{CI}$ ), ischemia-reperfusion plus low-dose propofol (group LP), ischemia-reperfusion plus moderate-dose propofol (group MP) and ischemia-reperfusion plus high-dose propofol (group HP).

Preparation of type 2 diabetic rats. T2DM were induced by the following protocol. All groups were fed a high-sugar, high-fat diet with free access to drinking water, at $22^{\circ} \mathrm{C}$ and $50 \%$ humidity, and maintained in a 12/12 h light and dark cycle. Rat feed was provided by Hebei Experimental Animals Center (Hebei, China). After 8 weeks, streptozotocin $(30 \mathrm{mg} / \mathrm{kg}$ body weight; Beijing Solarbio Science \& Technology Co., Ltd.) was injected into the abdomen to establish the T2DM model. Blood was obtained from the tail vein of rats and fasting glucose was detected. The model was considered to be successful if fasting glucose was $>14 \mathrm{~mol} / \mathrm{l}$ (15-18).

Establishment of myocardial ischemia-reperfusion injury model in rats. Subsequently, rats were anesthetized intraperitoneally with $1 \%$ pentobarbital $(40 \mathrm{mg} / \mathrm{kg})$. After anesthesia, tracheal intubation and mechanical ventilation were performed to connect the small animal ventilator (Hebei Medical University Instrument Factory). The femoral vein puncture catheter was connected using a micro infusion pump for the infusion of physiological saline or propofol. The right common carotid artery was connected to a pressure transducer to monitor HR, LVSP and $\pm \mathrm{dp} / \mathrm{dt}_{\max }$. Following the stabilization of blood pressure and HR, rats were placed in the right lateral decubitus position. The left thoracotomy, scissors and thread were placed below the left anterior descending coronary artery and polyethylene tubes were inserted between the myocardium and the ligature.

Rats in the CC group received an intravenous infusion of physiological $(0.9 \%)$ saline $\left(3 \mathrm{ml} / \mathrm{kg}^{-1} \bullet \mathrm{h}^{-1}\right)$ for $10 \mathrm{~min}$, with no ligation. Rats in the CI group received a $10 \mathrm{~min}$ intravenous infusion of normal saline $\left(3 \mathrm{ml} / \mathrm{kg}^{-1} \bullet \mathrm{h}^{-1}\right)$ followed by occlusion of the left anterior descending coronary artery for 30 min and $2 \mathrm{~h}$ of reperfusion. The LP, MP and HP groups rats received a $10 \mathrm{~min}$ intravenous infusion of propofol $\left(6 \mathrm{mg} / \mathrm{kg}^{-1} \bullet \mathrm{h}^{-1}\right),\left(12 \mathrm{mg} / \mathrm{kg}^{-1} \bullet \mathrm{h}^{-1}\right)$ and $\left(24 \mathrm{mg} / \mathrm{kg}^{-1} \bullet \mathrm{h}^{-1}\right)$ (equal volume of drugs with different concentrations), respectively. Each administration was followed by the occlusion of the left anterior descending coronary artery for $30 \mathrm{~min}$ and $2 \mathrm{~h}$ of reperfusion. Euthanasia was performed $2 \mathrm{~h}$ after reperfusion to obtain myocardial tissue.

Powerlab/8s (ADInstruments) was used to record heart rate (HR), left ventricular systolic pressure (LVSP) and the rate $\left(\mathrm{dP} / \mathrm{dt}_{\max }\right)$ of left ventricular pressure rise in early systole $\left( \pm \mathrm{DP} / \mathrm{dt}_{\max }\right)$.

ELISA method. Using an ELISA, cardiac troponin T (cTnT) levels, superoxide dismutase (SOD) and malondialdehyde (MDA) were measured. (cTnT ELISA kit; cat. no. E02T0017; SOD ELISA kit; cat. no. a001-1; MDA ELISA kit; cat. no. E02M0023; all from Shanghai Lanji Biotechnology Co., Ltd.).

At the time of reperfusion for $2 \mathrm{~h}, 2 \mathrm{ml}$ blood was collected from the abdominal aorta of rats in each group and centrifuged at $1,000 \mathrm{x} \mathrm{g} / \mathrm{min}$ for $15 \mathrm{~min}$ at $4^{\circ} \mathrm{C}$. The supernatant was taken and stored in refrigerator at $-80^{\circ} \mathrm{C}$ for testing. All specimens and kits were rewarmed after the collection of each group. In the blank microholes of the enzyme standard plate, $100 \mu \mathrm{l}$ standard substances were added, $100 \mu \mathrm{l}$ samples were added and $100 \mu 1$ PBS (pH 7.0-7.2) was added to the blank control group. A total of $50 \mu \mathrm{l}$ enzyme labeling solution was added to each hole (except the blank control hole). The enzyme standard plate was sealed and incubated at $37^{\circ} \mathrm{C}$ for $1 \mathrm{~h}$ at a constant temperature. The seal film was removed, the liquid discarded and the plate was thoroughly and dry rinsed. A total of $50 \mu \mathrm{l}$ chromogenic agent $\mathrm{A}$ and $50 \mu \mathrm{l}$ chromogenic agent $\mathrm{B}$ was added to each well, agitated and mixed in the dark at $37^{\circ} \mathrm{C}$ for $10-15 \mathrm{~min}$. A total of $50 \mu \mathrm{l}$ termination solution was added to each well to terminate the reaction (blue color immediately turns to yellow). After $10 \mathrm{~min}$, the blank well was adjusted to zero and the absorbance [optical density (OD) value] of each well was measured in sequence with the wavelength of $450 \mathrm{~nm}$. The linear regression equation of the standard curve was calculated according to the standard concentration and the corresponding OD value, and then the corresponding sample concentration was calculated by the regression equation according to the OD value of the sample.

Western blotting assay. After anesthesia, the rats' necks were dislocated and euthanized. The left anterior descending branch was collected to obtain samples of myocardial tissue and the ultrastructure of myocardial cells was observed using electron microscopy. Western blot analysis was used to detect LC3II, mTOR and p-mTOR expression in myocardial tissue.

Myocardial tissue from the ischemic zone were solubilized in RIPA lysing buffer [50 mM Tris (pH 7.4), $150 \mathrm{mM} \mathrm{NaCl}$, $1 \%$ NP- $40,0.5 \%$ sodium deoxycholate, $1 \mathrm{mM}$ PMSF]. Protein quantification was carried out by the modified Lowery method. Protein samples $(60 \mu \mathrm{g})$ were separated by $10 \%$ SDS-PAGE and transferred to PVDF membranes (Abcam). The membranes were blocked in 5\% skim milk for $2 \mathrm{~h}$ at room temperature and incubated with the primary antibodies $(1: 1,000)$ LC3II (Abcam; cat. no. ab48394), mTOR (Abcam; cat. no. ab2732) or p-mTOR (Abcam; cat. no. ab109268) overnight at $4^{\circ} \mathrm{C}$. Next, the membranes were incubated with secondary antibodies (horseradish peroxidase-labeled goat anti-mouse IgG; Abcam; cat. no. ab205719; $1: 1,000)$ at room temperature for $2 \mathrm{~h}$ and were washed three times (5 min/time) with TBST buffer (0.05\%Tween-20 in TBS). GAPDH (ProteinTech Group, Inc.; cat. no. 60004-1-Ig, 1:2,000) was used as an internal reference. Proteins were visualized using Immobilon ECL Ultra Western HRP Substrate (Millipore, cat. no. WBULS0500) and the blots were quantified using BandScan 5.0 software (Glyko, Inc.). 


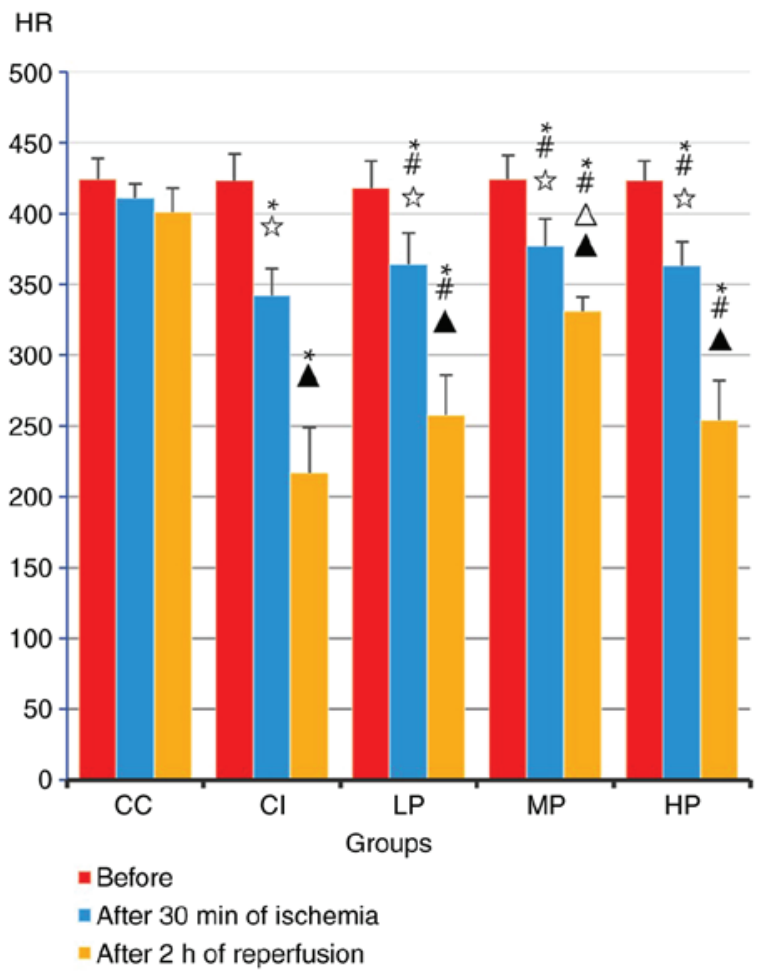

Figure 1. HR in different groups $(\mathrm{n}=10)$. Compared with the measurement taken at $30 \mathrm{~min}$ after ligation, HR significantly decreased at $2 \mathrm{~h}$ after reperfusion, except for the CC group $(\mathrm{P}<0.05)$. HR was significantly increased in the LP, MP and HP groups compared with the results at $30 \mathrm{~min}$ following ligation and $2 \mathrm{~h}$ following reperfusion $(\mathrm{P}<0.05)$. The MP group showed the greatest increase in HR levels $(\mathrm{P}<0.05)$, followed by the LP and HP group $(\mathrm{P}<0.05) .{ }^{*} \mathrm{P}<0.05$ vs. the $\mathrm{CC}$ group; ${ }^{\#} \mathrm{P}<0.05$ vs. group $\mathrm{CI} ;{ }^{\wedge} \mathrm{P}<0.05$ vs. group LP; ${ }^{*} \mathrm{P}<0.05$ vs. Before; ${ }^{\wedge} \mathrm{P}<0.05$ vs. after $30 \mathrm{~min}$ of ischemia. HR, heart rate; $\mathrm{CC}$, Sham-operation; CI, ischemia-reperfusion; LP, ischemia-reperfusion plus low-dose propofol; MP, ischemia-reperfusion plus moderate-dose propofol; HP, ischemia-reperfusion plus high-dose propofol.

Electron microscopy. After reperfusion for $2 \mathrm{~h}$, the rats were euthanized and the myocardial ischemic area was taken and cut into $1 \mathrm{~mm}$ pieces. A total of $4 \%$ glutaraldehyde solution was used for fixation at $4^{\circ} \mathrm{C}$ for $24 \mathrm{~h}$ and washed with $0.1 \mathrm{~mol} / 1$ PBS 3 times. $1 \%$ osmium acid $-1.5 \%$ potassium ferricyanide at $4^{\circ} \mathrm{C}$ was used to fix the tissue again for $1.5 \mathrm{~h}, 0.1 \mathrm{~mol} / \mathrm{l} \mathrm{PBS}$ rinse 3 times. Ethanol-pyruvate was dehydrated step by step. Anhydrous acetone-epoxy resin 618 embedding agent (1:1) was fixed at $35^{\circ} \mathrm{C}$ for $1.5 \mathrm{~h}$. The pure 618 embedding agent was fixed at $35^{\circ} \mathrm{C}$ for $12 \mathrm{~h}, 45^{\circ} \mathrm{C}$ for $12 \mathrm{~h}$ and $60^{\circ} \mathrm{C}$ for 3 days. Ultrathin sections of 70-80 nm were prepared. Uranium acetate and lead citrate were dyed at $22^{\circ} \mathrm{C}$ for $5 \mathrm{~min}$, then washed with distilled water. The ultrastructure of myocardium was observed under transmission electron microscope (Hitachi, Ltd.; model: h-7500) (magnification, x15,000).

Statistical analyses. SPSS v 16.0 (SPSS, Inc.) was used for all statistical analyses. Data are presented as the mean \pm SD. Hemodynamics were compared and analyzed within groups and between groups using multivariate analysis of variance (ANOVA). The level of cTnT, SOD, MDA, LC3II, mTOR and p-mTOR were compared using a one-way ANOVA, followed by a post hoc Tukey's test. $\mathrm{P}<0.05$ was considered to indicate a statistically significant difference. All experiments were performed in triplicates.

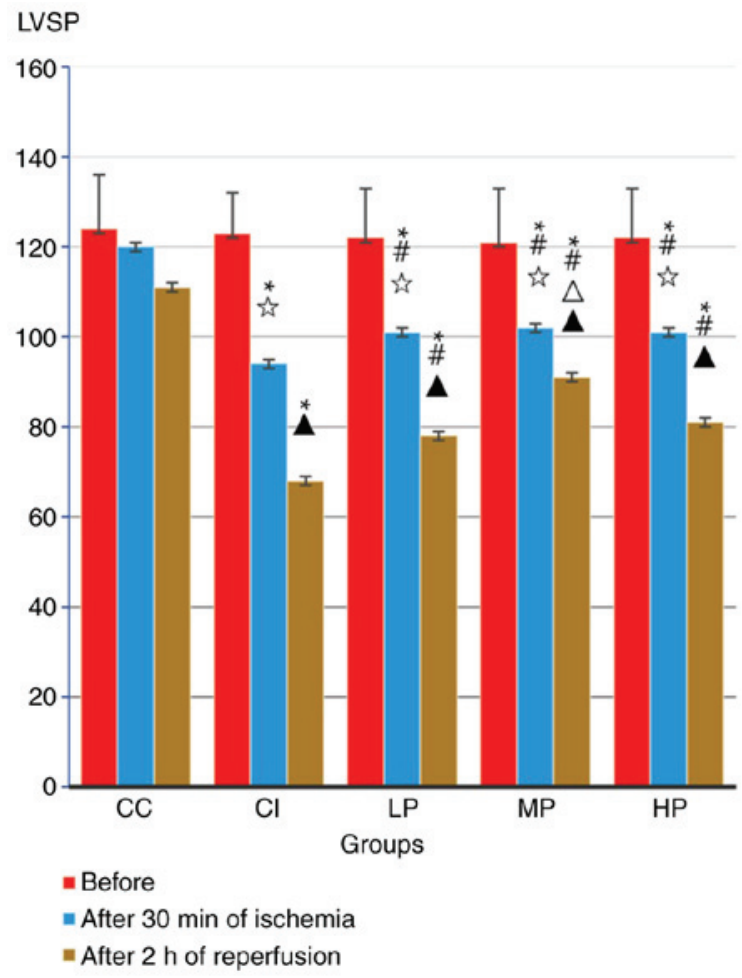

Figure 2. LVSP in different groups $(\mathrm{n}=10)$. Compared with the measurement taken at $30 \mathrm{~min}$ after ligation, LVSP significantly decreased at $2 \mathrm{~h}$ after reperfusion, except for in the CC group $(\mathrm{P}<0.05)$. LVSP was significantly increased in the LP, MP and HP groups compared with the results at 30 min following ligation and $2 \mathrm{~h}$ following reperfusion $(\mathrm{P}<0.05)$. The LVSP levels in the MP group increased showed the greatest increase $(\mathrm{P}<0.05)$, followed by the LP and HP group $(\mathrm{P}<0.05)$. ${ }^{*} \mathrm{P}<0.05$ vs. the $\mathrm{CC}$ group; ${ }^{\mathrm{P}} \mathrm{P}<0.05$ vs. group $\mathrm{CI} ;{ }^{\wedge} \mathrm{P}<0.05$ vs. group LP; ${ }^{\star} \mathrm{P}<0.05$ vs. Before; ${ }^{\wedge} \mathrm{P}<0.05$ vs. after $30 \mathrm{~min}$ of ischemia. LVSP, left ventricular systolic pressure; CC, Sham-operation; $\mathrm{CI}$, ischemia-reperfusion; LP, ischemia-reperfusion plus low-dose propofol; MP, ischemia-reperfusion plus moderate-dose propofol; HP, ischemia-reperfusion plus high-dose propofol.

\section{Results}

Hemodynamic parameters. No significant differences were exhibited in HR, LVSP, +dp/dt and -dp/dt, prior to ischemia, in all groups. When compared with measurements taken prior to ischemia, HR, LVSP, +dp/dt and -dp/dt significantly decreased following ligation for $30 \mathrm{~min}$, except for the CC group $(\mathrm{P}<0.05$; Figs. 1-4). Compared with the measurement taken at $30 \mathrm{~min}$ after ligation, HR, LVSP, $+\mathrm{dp} / \mathrm{dt}$ and $-\mathrm{dp} / \mathrm{dt}$ significantly decreased at $2 \mathrm{~h}$ after reperfusion compared with the before group, except for the $\mathrm{CC}$ group $(\mathrm{P}<0.05)$.

HR, LVSP, +dp/dt and -dp/dt were significantly increased in the LP, MP and HP groups compared with the results at 30 min following ligation and $2 \mathrm{~h}$ following reperfusion $(\mathrm{P}<0.05)$. The MP group HR, LVSP, $+\mathrm{dp} / \mathrm{dt}$ and $-\mathrm{dp} / \mathrm{dt}$ levels increased significantly, followed by the LP and HP group $(\mathrm{P}<0.05$; Figs. 1-4).

Electron microscopy. At $2 \mathrm{~h}$ following reperfusion, ultrastructural changes of myocardial tissue were observed in all groups using electron microscopy. The arrangement of myocardial cells in the CC group was more orderly and no fusion was observed between mitochondrial cristae and membranes. In the CI group, myocardial cells were disordered, highly edematous, mitochondrial cristae and membranes were dissolved and 


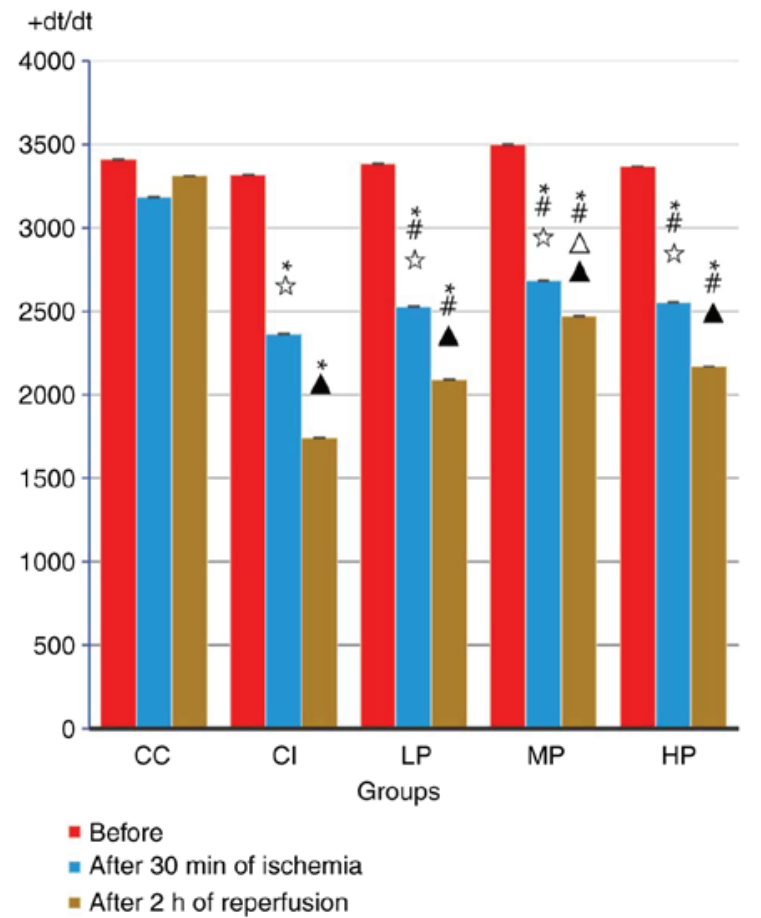

Figure 3. $+\mathrm{dp} / \mathrm{dt}$ in different groups $(\mathrm{n}=10)$. Compared with the measurement taken at $30 \mathrm{~min}$ after ligation, +dp/dt significantly decreased at $2 \mathrm{~h}$ after reperfusion, except for the $\mathrm{CC}$ group $(\mathrm{P}<0.05)$. $+\mathrm{dp} / \mathrm{dt}$ was significantly increased in the LP, MP and HP groups compared with the results at 30 min following ligation and $2 \mathrm{~h}$ following reperfusion $(\mathrm{P}<0.05)$. The $+\mathrm{dp} / \mathrm{dt}$ levels in the MP group showed the greatest increase $(\mathrm{P}<0.05)$, followed by the LP and HP group $(\mathrm{P}<0.05) .{ }^{*} \mathrm{P}<0.05$ vs. the $\mathrm{CC}$ group; ${ }^{\#} \mathrm{P}<0.05$ vs. group $\mathrm{CI} ;{ }^{\Delta} \mathrm{P}<0.05$ vs. group LP; ${ }^{\wedge} \mathrm{P}<0.05$ vs. Before; ${ }^{\wedge} \mathrm{P}<0.05$ vs. after 30 min of ischemia. $\mathrm{CC}$, Sham-operation; CI, ischemia-reperfusion; LP, ischemia-reperfusion plus low-dose propofol; MP, ischemia-reperfusion plus moderate-dose propofol; HP, ischemia-reperfusion plus high-dose propofol.

changes in the vacuole were observed. Compared with the CI group, the myocardial cells in the MP group were slightly disordered, exhibited mild edema and exhibited partly dissolved mitochondrial cristae and membrane rupture. The degree of injury in myocardial cells and mitochondria in the LP and HP group was between the CI and MP group (Figs. 5-9).

Serum concentrations of cTnT, SOD and MDA. Following $2 \mathrm{~h}$ of reperfusion, compared with the CC group, SOD significantly decreased in all other groups $(\mathrm{P}<0.05)$, and the $\mathrm{cTnT}$ and MDA levels significantly increased $(\mathrm{P}<0.05$; Table I). Compared with the CI group, the concentration of SOD in the MP group decreased significantly $(\mathrm{P}<0.05)$ and the concentrations of cTnT and MDA were decreased $(\mathrm{P}<0.05)$. The LP and HP group also exhibited significant changes in SOD, cTnT and MDA levels $(\mathrm{P}<0.05$; Table I).

Protein expression of LC3II, mTOR and p-mTOR. Following $2 \mathrm{~h}$ of reperfusion, compared with the CC group, LC3II and mTOR expression was significantly increased in all other groups $(\mathrm{P}<0.05)$, and $\mathrm{p}$-mTOR expression was significantly decreased $(\mathrm{P}<0.05)$. Compared with the $\mathrm{CI}$ group, MP group mTOR expression decreased significantly $(\mathrm{P}<0.05)$ and p-mTOR expression increased significantly $(\mathrm{P}<0.05)$, The LP and HP group also exhibited significant changes in mTOR and p-MTOR expression ( $\mathrm{P}<0.05$; Table II; Fig. 10).

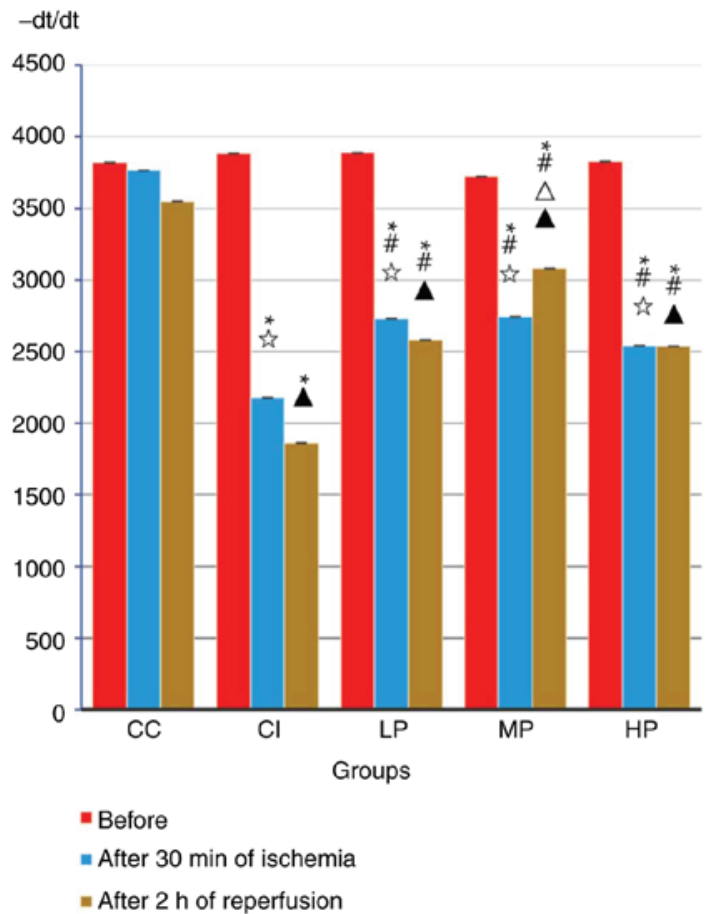

Figure 4. $-\mathrm{dp} / \mathrm{dt}$ in different groups $(\mathrm{n}=10)$. Compared with the measurement taken at $30 \mathrm{~min}$ after ligation, -dp/dt significantly decreased at $2 \mathrm{~h}$ after reperfusion, except for the $\mathrm{CC}$ group $(\mathrm{P}<0.05)$. $-\mathrm{dp} / \mathrm{dt}$ was significantly increased in the LP, MP and HP groups compared with the results at 30 min following ligation and $2 \mathrm{~h}$ following reperfusion $(\mathrm{P}<0.05)$. The $-\mathrm{dp} / \mathrm{dt}$ levels in the MP group showed the greatest increase $(\mathrm{P}<0.05)$, followed by the LP and HP group $(\mathrm{P}<0.05)$. ${ }^{*} \mathrm{P}<0.05$ vs. the $\mathrm{CC}$ group; ${ }^{\text {\#}} \mathrm{P}<0.05$ vs. group $\mathrm{CI} ;{ }^{\Delta} \mathrm{P}<0.05$ vs. group LP; ${ }^{\circledR} \mathrm{P}<0.05$ vs. Before; ${ }^{\wedge} \mathrm{P}<0.05$ vs. after 30 min of ischemia. $C \mathrm{C}$, Sham-operation; CI, ischemia-reperfusion; LP, ischemia-reperfusion plus low-dose propofol; MP, ischemia-reperfusion plus moderate-dose propofol; $\mathrm{HP}$, ischemia-reperfusion plus high-dose propofol.

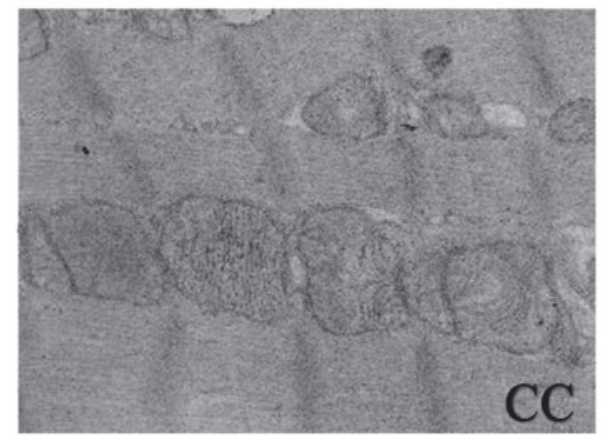

Figure 5. Group CC of myocardial ischemia reperfusion injury in type 2 diabetes mellitus rats under transmission electron microscopy. Myocardial fibrosis, along with integrity of the membrane and cristae of mitochondria are clearly visible. Also, the integrity of inner and outer nuclear membranes of nuclei is retained, and nucleoli can be seen clearly (Magnification, x15,000). $\mathrm{CC}$, sham-operation.

\section{Discussion}

The polypeptide subunit of troponin complex, cTnT, is a specific antigen of cardiac myocytes. Elevated serum cTnT can reflect myocardial structural protein damage. A parallel relationship exists between cTnT level and the degree of myocardial cell injury (19). Therefore, cTnT is used as a specific marker of 


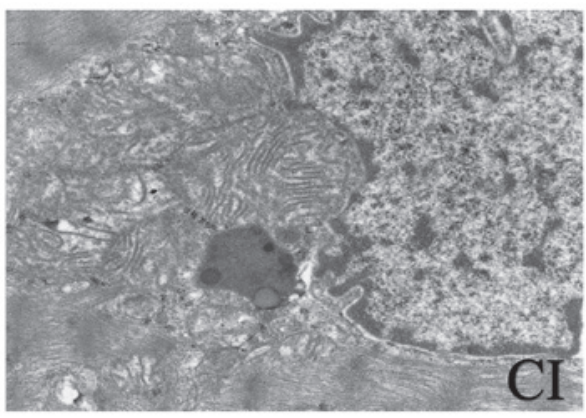

Figure 6. Group CI of myocardial ischemia reperfusion injury in type 2 diabetes mellitus rats under transmission electron microscopy. Swelling of mitochondria, rupture and disappearance of mitochondrial membranes, dissolution of edema between mitochondria, absence of chromatin, disappearance of the outer nuclear envelope, disappearance of some inner and outer nuclear envelopes, and perinuclear edema can be seen. Also, mitochondrial degeneration and necrosis of myocardial fibers, indistinct sarcomeres, and an absence of muscle-fiber structure is revealed (Magnification, x15,000). CI, ischemia-reperfusion.

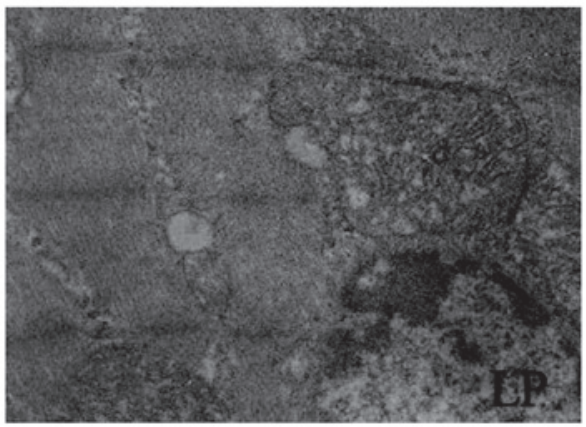

Figure 7. Group LP of myocardial ischemia reperfusion injury in type 2 diabetes mellitus rats under transmission electron microscopy. Mitochondrial edema, mitochondrial films and partial disappearance of mitochondria are noted. Also, high-density chromatin, partial disappearance of the outer layer of nuclear films (but not of nuclear film within layers) mild edema between muscle fibers, mild damage to myocardial fibers and comparatively neat muscle arrangement are noted (Magnification, x15,000). LP, ischemia-reperfusion plus low-dose propofol.

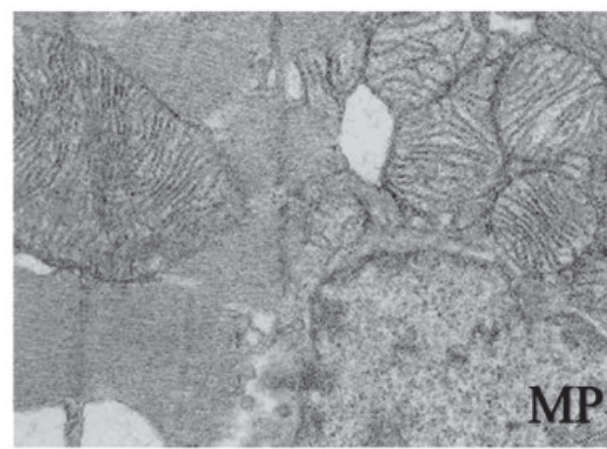

Figure 8. Group MP of myocardial ischemia reperfusion injury in type 2 diabetes mellitus rats under transmission electron microscopy. Some mitochondrial edema is present, along with chromatin-dense masses but no obvious perinuclear edema; lighter myocardial fibrosis is noted and sarcomeres are aligned (Magnification, x15,000). MP, ischemia-reperfusion plus moderate-dose propofol.

myocardial injury and due to it being elevated in patients with coronary artery disease or heart failure, has also been investigated as a prognostic marker (20). Among the number of clinical

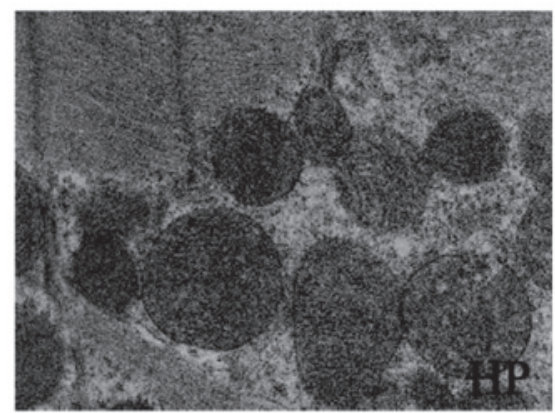

Figure 9. Group HP of myocardial ischemia reperfusion injury in type 2 diabetes mellitus rats under transmission electron microscopy. Mitochondrial edema, mitochondrial films, chromatin-dense masses, nuclear films within the layer and partial disappearance of the outer layer of nuclear films (but not of nuclear films within layers) are observed. Mild edema between muscle fibers, mild damage to myocardial fibers and comparatively neatly arranged muscle sections can be seen (Magnification, x15,000). HP, ischemia-reperfusion plus high-dose propofol.

Table I. cTnT, SOD and MDA concentration of blood serum of myocardial ischemia reperfusion injury in rats with diabetes.

\begin{tabular}{lcll}
\hline Group & cTnT $(\mathrm{ng} / \mathrm{ml})$ & SOD $(\mathrm{U} / \mathrm{ml})$ & MDA $(\mathrm{nmol} / \mathrm{ml})$ \\
\hline CC & $4.34 \pm 1.34$ & $160.27 \pm 5.15$ & $2.75 \pm 0.55$ \\
CI & $15.26 \pm 0.74^{\mathrm{a}}$ & $112.49 \pm 7.95^{\mathrm{a}}$ & $5.21 \pm 0.24^{\mathrm{a}}$ \\
LP & $12.62 \pm 1.00^{\mathrm{a}, \mathrm{b}}$ & $122.94 \pm 5.38^{\mathrm{a}, \mathrm{b}}$ & $4.51 \pm 0.20^{\mathrm{a}, \mathrm{b}}$ \\
MP & $9.50 \pm 1.90^{\mathrm{a}-\mathrm{c}}$ & $147.05 \pm 7.83^{\mathrm{a}-\mathrm{c}}$ & $3.70 \pm 0.16^{\mathrm{a}-\mathrm{c}}$ \\
HP & $12.40 \pm 1.66^{\mathrm{a}, \mathrm{b}}$ & $130.01 \pm 6.16^{\mathrm{a}, \mathrm{b}}$ & $4.40 \pm 0.27^{\mathrm{a}, \mathrm{b}}$ \\
\hline
\end{tabular}

${ }^{\mathrm{a}} \mathrm{P}<0.05$ vs. group $\mathrm{CC} .{ }^{\mathrm{b}} \mathrm{P}<0.05$ vs. group $\mathrm{CI}$., ${ }^{\mathrm{c}} \mathrm{P}<0.01$ vs. group LP. $(\mathrm{n}=7, \bar{x} \pm s) . \mathrm{MDA}$, malondialdehyde; SOD, superoxide dismutase; cTnT, cardiac troponin T; CC, Sham-operation; CI, ischemia-reperfusion; LP, ischemia-reperfusion plus low-dose propofol; MP, ischemia-reperfusion plus moderate-dose propofol; $\mathrm{HP}$, ischemia-reperfusion plus high-dose propofol.

Table II. The expression levels of LC3 II and mTOR/p-mTOR of ischemia-reperfusion myocardium in jury in diabetes 2 rats $(\mathrm{n}=7, \bar{x} \pm s)$.

\begin{tabular}{llll}
\hline Group & \multicolumn{1}{c}{ LC3II } & \multicolumn{1}{c}{ mTOR } & p-mTOR \\
\hline CC & $0.30 \pm 0.04$ & $1.06 \pm 0.04$ & $0.88 \pm 0.02$ \\
CI & $1.03 \pm 0.12^{\mathrm{a}}$ & $1.41 \pm 0.03^{\mathrm{a}}$ & $0.67 \pm 0.04^{\mathrm{a}}$ \\
LP & $0.76 \pm 0.09^{\mathrm{a}, \mathrm{b}}$ & $1.25 \pm 0.04^{\mathrm{a}, \mathrm{b}}$ & $0.78 \pm 0.02^{\mathrm{a}, \mathrm{b}}$ \\
MP & $0.51 \pm 0.08^{\mathrm{a}-\mathrm{c}}$ & $1.18 \pm 0.06^{\mathrm{a}-\mathrm{c}}$ & $0.84 \pm 0.01^{\mathrm{a}-\mathrm{c}}$ \\
HP & $0.77 \pm 0.13^{\mathrm{a}, \mathrm{b}}$ & $1.28 \pm 0.02^{\mathrm{a}, \mathrm{b}}$ & $0.78 \pm 0.05^{\mathrm{a}, \mathrm{b}}$ \\
\hline
\end{tabular}

${ }^{\mathrm{a}} \mathrm{P}<0.05$ vs. group $\mathrm{CC}$. ${ }^{\mathrm{b}} \mathrm{P}<0.05$ vs. group $\mathrm{CI}$. ${ }^{\mathrm{c}} \mathrm{P}<0.01$ vs. group LP. $\mathrm{p}$, phosphorylated; mTOR, mammalian target of rapamycin; $\mathrm{CC}$, Sham-operation; CI, ischemia-reperfusion; LP, ischemia-reperfusion plus low-dose propofol; MP, ischemia-reperfusion plus moderate-dose propofol; HP, ischemia-reperfusion plus high-dose propofol.

and biochemical indices that are used for the diagnosis of myocardial injury, cTnT is considered to be the 'gold standard'. 


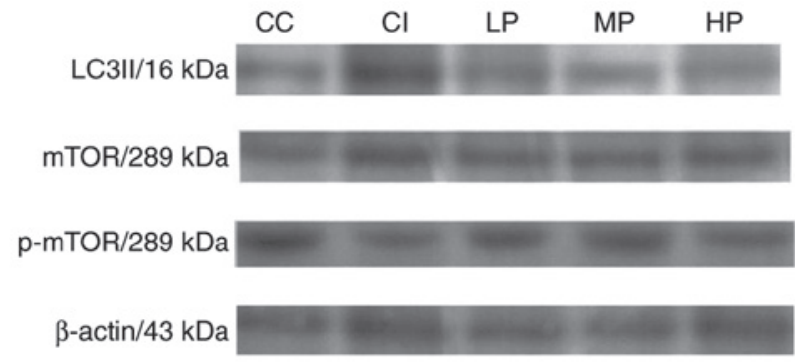

Figure 10. Expression of LC3 II, mTOR and p-mTOR protein was observed by western blotting. P-mTOR, phosphorylated-mammalian target of rapamycin.

The current study demonstrated that cTnT serum levels in the LP, MP and HP groups were decreased, and HR and LVSP levels in the propofol groups were increased, when compared with the $\mathrm{CI}$ group. These results revealed that propofol exhibits myocardial protective effects on rats with T2DM and the medium dose was indicated to be most effective.

SOD is a natural oxygen free radical scavenger that is located in the myocardium and is also an important antioxidant enzyme. SOD activity can reflect the scavenging ability of the organism to produce oxygen free radicals. In the process of myocardial ischemia reperfusion, a large amount of oxygen free radicals is produced, which leads to a decrease in SOD concentration and activity (21). A previous study has demonstrated that SOD content can reflect the severity of myocardial injury (22). However, previous reports investigating the beneficial effects of other plant extracts on I/R induced injury revealed that improved conditions were due to the antioxidant properties of their constituents (23-25).

MDA is the most important metabolite of lipid peroxidation in cardiac myocytes and has been indicated to cross-link proteins and nucleic acids in cardiomyocytes. During cardiomyocyte mutation, senescence, denaturation and death, MDA content has been revealed to increase during myocardial cell injury. Therefore, the detection of MDA is often used to assess the extent of myocardial oxidative damage during myocardial ischemia-reperfusion injury (7).

The results of the current study demonstrated that SOD concentrations in the LP, MP and HP groups were increased, and MDA levels in the propofol groups were decreased. These results suggested that propofol exhibits a myocardial protective effect on rats with T2DM.

Under normal conditions, $60 \%$ of the energy required for cardiomyocytes to function is gained from fatty acid oxidation. In ischemia and hypoxia conditions, the energy needed for the operation of myocardial cells is mainly obtained via the anaerobic glycolysis of glucose (26). In patients with diabetes, glucose and lipid metabolism are disordered, and the use of energy gained from anaerobic glycolysis is impaired. In patients with diabetes, when myocardial cells are ischemic, they may suffer from energy supply disorder and their self-protection ability decreases (27). These results suggest that diabetes aggravates myocardial injury.

Anesthesia with intravenous propofol is often used to inhibit lipid peroxidation, improve mitochondrial function (26), protect the myocardium and reduce MIRI in rats (27). Propofol also improves the function of vascular endothelial cells and promotes anti-apoptotic protein expression, and can therefore reduce MIRI in T2DM. The influence of propofol on hemodynamics is associated with the dose quantity and speed of injection. The most commonly used intravenous maintenance dose is $4-12 \mathrm{mg} / \mathrm{kg}^{-1} \cdot \mathrm{h}^{-1}$. A previous study demonstrated that mean arterial pressure and cardiac output are not significantly altered by an intravenous infusion of propofol with $8.4-18 \mathrm{mg} / \mathrm{kg}^{-1} \mathrm{~h}^{-1}$ (28). Propofol can markedly attenuate autophagic processes via decreased expression of autophagy-related proteins in vitro and in vivo. This inhibition can improve cell survival, which provides a novel explanation for the pleiotropic effects of propofol that benefit the nervous system (29).

The current study adopts the traditional preparation methods of a T2DM model (17,30-32). A fasting glucose level of $14 \mathrm{~mol} / \mathrm{l}$ or greater in rats is considered to indicate a model of T2DM. The results revealed that HR, LVSP and $\pm \mathrm{DP} / \mathrm{dtmax}$ were reduced upon occlusion for $30 \mathrm{~min}$ and reperfusion for $2 \mathrm{~h}$, when compared with the preceding arterial occlusion. This indicated that the myocardial ischemia reperfusion model had been successfully established.

The results of the current study demonstrated that, compared with the CI group, the concentrations of plasma cTnT and MDA in the propofol groups were decreased, plasma SOD concentration was increased and HR and LVSP levels were increased. The damage exhibited in myocardial cells was minor when observed under an electron microscope. The degree of injury in the MP group was the smallest, followed by the LP and HP group. These results suggested that propofol inhibited myocardial cell peroxidation and alleviated myocardial ischemia-reperfusion injury in rats with T2DM. The intravenous infusion of propofol at a speed of $12 \mathrm{mg} / \mathrm{kg}^{-1} \cdot \mathrm{h}^{-1}$ was indicated to be optimal.

Autophagy is the process of transporting intracellular denatured or senescent proteins and damaged organelles to lysosomes for digestion and degradation. Autophagy is a cell defense mechanism against an adverse environment. Autophagy has also been associated with the pathological process of a variety of disease types. Previous studies $(33,34)$ have indicated that, under ischemia and hypoxia conditions, cardiomyocytes can activate autophagy, and can enhance the expression of mTOR and LC3II. An appropriate level of autophagy can protect cardiomyocytes, however, excessive autophagy may lead to injury of myocardial cell under ischemia and hypoxia (35). A number of studies have demonstrated that autophagy is closely associated with T2DM and myocardial ischemia-reperfusion injury (36-38). If the myocardial cells are exposed to extreme ischemia, the excessive activation of autophagy during reperfusion may promote apoptosis (39). In the current study, LC3II and $\mathrm{mTOR} / \mathrm{p}$-mTOR expression in rats with T2DM was investigated after $2 \mathrm{~h}$ of myocardial ischemia and reperfusion. The effect of propofol on autophagy was also analyzed during myocardial ischemia-reperfusion injury.

The results of the current study revealed that, compared with the CC group, LC3II and mTOR expression increased, and the expression of p-mTOR was decreased in the CI group. Compared with the CI group, mTOR expression was decreased in the MP group and p-mTOR expression increased, followed by 
the LP and HP group. These results demonstrated that propofol inhibited autophagy during myocardial ischemia reperfusion injury in rats with T2DM, while the optimal propofol infusion was $12 \mathrm{mg} / \mathrm{kg}^{-1} \cdot \mathrm{h}^{-1}$.

The present study demonstrated that the administration of propofol in T2DM rats upregulated p-mTOR expression in myocardium, decreased the expression of mTOR and LC3II, inhibited excessive autophagy and oxidative stress in the myocardium and reduced the myocardial ischemia-reperfusion injury, with the optimal infusion rate of $12 \mathrm{mg} / \mathrm{kg}^{-1} \cdot \mathrm{h}^{-1}$.

\section{Acknowledgements}

Not applicable.

\section{Funding}

Planning project of Hebei Provincial Science and Technology Department (grant no. 12276104D-35).

\section{Availability of data and materials}

The datasets used and/or analyzed during the present study are available from the corresponding author on reasonable request.

\section{Authors' contributions}

YW, KZ, XQ and GY performed the experiments. YW and XQ performed the literature search. HW conceptualized the study. YW, ZZ and BY analyzed the data. YW and KZ designed and produced the figures. YW created the tables. YW and BY wrote the manuscript. HW reviewed the paper. All authors read and approved the final manuscript.

\section{Ethics approval and consent to participate}

The current study has been examined by the Animal Welfare and Ethical Committee of Hebei University.

\section{Patient consent for publication}

Not applicable.

\section{Competing interests}

The authors declare that they have no competing interests.

\section{References}

1. Shaw JE, Sicree RA and Zimmet PZ: Global estimates of the prevalence of diabetes for 2010 and 2030. Diabetes Res Clin Pract 87: 4-14, 2010

2. Unwin N, Gan D and Whiting D: The IDF diabetes atlas: Providing evidence, raising awareness and promoting action. Diabetes Res Clin Pract 87: 2-3, 2010.

3. Alessandra SMM, Lucianne RMT, Roberta AC, Catia CSP, Carlos AN and Marilia Marilia de BG: Impact of diabetes on cardiovascular disease: An update. Int J Hyperten 2013: Article ID $653789,2013$.

4. Tonelli M, Muntner P, Lloyd A, Manns BJ, Klarenbach S, Pannu N, James MT, Hemmelgarn BR, Alberta Kidney and Disease Network: Risk of coronary events in people with chronic kidney disease compared with those with diabetes: A population-level cohort study. Lancet 380: 807-814, 2012.
5. Cho DK, Choi DH and Cho JY: Effect of treadmill exercise on skeletal muscle autophagy in rats with obesity induced by a high-fat diet. J Exerc Nutrition Biochem 21: 26-34, 2017.

6. Diaz-Morales N, Iannantuoni F, Escribano-Lopez I, Bañuls C, Rovira-Llopis S, Sola E, Rocha M, Hernandez-Mijares A and Victor VM: Does metformin modulate endoplasmic reticulum stress and autophagy in type 2 diabetic peripheral blood mononuclear cells. Antioxid Redox Signal 28: 1562-1569, 2018.

7. Noh HS, Shin IW, Ha JH, Hah YS, Baek SM and Kim DR: Propofol protects the autophagic cell death induced by the ischemia/reperfusion injury in rats. Mol Cells 30: 455-460, 2010.

8. Hwang JY, Gertner M, Pontarelli F, Court-Vazquez B Bennett MV, Ofengeim D and Zukin RS: Global ischemia induces lysosomal-mediated degradation of mTOR and activation of autophagyin hippocampal neurons destined to die. Cell Death Differ 24: 317-329, 2017.

9. Chang H, Li X, Cai Q, Li C, Tian L, Chen J, Xing X, Gan Y, Ouyang W and Yang Z: The PI3K/Akt/mTOR pathway is involved in CVB3-induced autophagy of HeLa cells. Int J Mol Med 40: 182-192, 2017.

10. Schaaf MB, Keulers TG, Vooijs MA and Rouschop KM: LC3/GABARAP family proteins: Autophagy-(un)related functions. FASEB J 30: 3961-3978, 2016.

11. Gao Y, Yang H, Chi J, Xu Q, Zhao L, Yang W, Liu W and Yang W: Hydrogen gas attenuates myocardial ischemia reperfusion injury independent of postconditioning in rats by attenuating endoplasmic reticulum stress-induced autophagy. Cell Physiol Biochem 43: 1503-1514, 2017.

12. Yao X, Li Y, Tao M, Wang S, Zhang L, Lin J, Xia Z and Liu HM: Effects of glucose concentration on propofol cardioprotection against myocardial ischemia reperfusion injury in isolated rat hearts. J Diabetes Res 2015: 592028, 2015.

13. Liu Y, Shi L, Liu C Zhu G, Li H, Zhao H and Li S: Effect of combination therapy of propofol and sevoflurane on MAP2K3 level and myocardialapoptosis induced by ischemia-reperfusion in rats. Int J Clin Exp Med 8: 6427-6435, 2015.

14. Sirvinskas E, Kinderyte A, Trumbeckaite S, Lenkutis T, Raliene L, Giedraitis S, Macas A and Borutaite V: Effects of sevoflurane vs. propofol on mitochondrial functional activity after ischemia-reperfusioninjury and the influence on clinical parameters in patients undergoing CABG surgery with cardiopulmonary bypass. Perfusion 30: 590-595, 2015.

15. Reed MJ, Meszaros K, Entes LJ, Claypool MD, Pinkett JG, Gadbois TM and Reaven GM: A new rat model of type 2 diabetes: The fat-fed, streptozotocin-treated rat. Metabolism 49: 1390-1394, 2000

16. Srinivasan K, Viswanad B, Asrat L, Kaul CL and Ramarao P: Combination of high-fat diet-fed and low-dose streptozotocintreated rat: A model for type 2 diabetes and pharmacological screening. Pharmacol Res 52: 313-320, 2005.

17. Zhang M, Lv XY, Li J, Xu ZG and Chen L: The characterization of high-fat diet and multiple low-dose streptozotocin induced type 2 diabetes rat model. Exp Diabetes Res 2008: 704045, 2008.

18. Zhang F, Ye C, Li G, Ding W, Zhou W, Zhu H, Chen G, Luo T, Guang M, Liu Y, et al: The rat model of Type 2 diabetic mellitus and its glycometabolism characters. Exp Anim 52: 401-407, 2003.

19. Mahdavi L, Abdollahi MH, Entezari A, Salehi E, Hosseini H, Moshtaghioon SH, Rafie A and Rahimianfar AA: The effect of sevoflurane versus propofol anesthesia on troponin I after congenital heart surgery, a randomized clinical trial. Adv Biomed Res 4: 86, 2015.

20. Abiko M, Inai K, Shimada E, Asagai S and Nakanishi T: The prognostic value of high sensitivity cardiac troponin $\mathrm{T}$ in patients with congenital heart disease. J Cardiol 71: 389-393, 2018.

21. Laskey WK: Brief repetitive balloon occlusions enhance reperfusion during percutaneous coronary intervention for acute myocardial lnfarction: A pilot study. Catheter Cardiovasc Interv 65: 361-367, 2005.

22. Pytel E, Olszewska-Banaszczyk M, Koter-Michalak M and Broncel M: Increased oxidative stress and decreased membrane fluidity in erythrocytes of CAD patients. Biochem Cell Biol 91: 315-318, 2013.

23. Allahyari S, Delazar A and Najafi M: Evaluation of general toxicity, anti-oxidant activity and effects of ficus carica leaves extract on ischemia/reperfusion injuries in isolated heart of rat. Adv Pharm Bull 4 (Suppl 2): S577-S582, 2014.

24. Malakul W, Ingkaninan K, Sawasdee P and Woodman OL: The ethanolic extract of Kaempferia parviflora reduces ischaemic injury in rat isolated hearts. J Ethnopharmacol 137: 184-191, 2011. 
25. Sadeghi N, Dianat M, Badavi M and Malekzadeh A: Cardioprotective effect of aqueous extract of Chichorium intybus on ischemia-reperfusion injury in isolated rat heart. Avicenna J Phytomed 5: 568-575, 2015.

26. Reinstadler SJ, Stiermaier T, Eitel C, Metzler B, de Waha S, Fuernau G, Desch S, Thiele H and Eitel I: Relationship between diabetes and ischaemic injury among patients with revascularized ST-elevation myocardial infarction. Diabetes Obes Metab 19: 1706-1713, 2017.

27. Katakam PV, Jordan JE, snipes JA, Tulbert CD, Miller AW and Busija DW: Myocardiai preconditioning against ischemia-reperfusion injury is abolished in Zucker obese rats with insulin resistance. Am J Physiol Regul Integr Comp Physiol 292: 920-926, 2007.

28. Oku K, Ohta M, Katoh T, Moriyama H, Kusano K and Fujinaga T: Cardiovascular effects of continuous propofol infusion in horses. J Vet Med Sci 68: 773-778, 2006.

29. Cui D, Wang L, Qi A, Zhou Q, Zhang X and Jiang W: Propofol prevents autophagic cell death following oxygen and glucose deprivation in PC12 cells and cerebral ischemia-reperfusion injury in rats. PLoS One 7: e35324, 2012.

30. Skovs $\varnothing$ S: Modeling type 2 diabetes in rats using high fat diet and streptozotocin. J Diabetes Investig 5: 350-358, 2014.

31. Salvador ÂC, Król E, Lemos VC, Santos SA, Bento FP, Costa CP, Almeida A, Szczepankiewicz D, Kulczyński B, Krejpcio Z, et al: Effect of elderberry (Sambucus nigra L.) extract supplementation in stz-induced diabetic rats fed with a high-fat diet. Int J Mol Sci 18: pii: E13, 2016.

32. Wang HJ, Jin YX, Shen W, Neng J, Wu T, Li YJ and Fu ZW: Low dose streptozotocin (STZ) combined with high energy intake can effectively induce type 2 diabetes through altering the related gene expression. Asia Pac J Clin Nutr 16 (Suppl 1): S412-S417, 2007.

33. Dai S, Xu Q, Liu S, Yu B, Liu J and Tang J: Role of autophagy and its signaling pathways in ischemia/reperfusion injury. Am J Transl Res 9: 4470-4480, 2017.
34. Zhao P, Zhang BL, Liu K, Qin B and Li ZH: Overexpression of miR-638 attenuated the effects of hypoxia/reoxygenation treatment on cell viability, cell apoptosis and autophagy by targeting ATG5 in the human cardiomyocytes. Eur Rev Med Pharmacol Sci 22: 8462-8471, 2018

35. Ravikumar B, Sarkar S, Davies JE, Futter M, Garcia-Arencibia M, Green-Thompson ZW, Jimenez-Sanchez M, Korolchuk VI, Lichtenberg M, Luo S, et al: Regulation of mammalian autophagy in physiology and pathophysiology. Physiol Rev 90: 1383-1435, 2010.

36. Jing YH, Zhang L, Gao LP, Qi CC, Lv DD, Song YF, Yin J and Wang DG: Autophagy plays beneficial effect on diabetic encephalopathy in type 2 diabetes: Studies in vivo and in vitro. Neuro Endocrinol Lett 38: 27-37, 2017.

37. Kanamori H, Takemura G, Goto K, Tsujimoto A, Mikami A, Ogino A, Watanabe T, Morishita K, Okada H, Kawasaki M and Minatoguchi S: Autophagic adaptations in diabetic cardiomyopathy differ between type 1 and 2 diabetes. Autophagy 11: 1146-1160, 2015

38. Chen-Scarabelli C, Agrawal PR, Saravolatz L, Abuniat C, Scarabelli G, Stephanou A, Loomba L, Narula J, Scarabelli TM and Knight $\mathrm{R}$ : The role and modulation of autophagy in experimental models of myocardial ischemia-reperfusion injury. J Geriatr Cardiol 11: 338-348, 2014.

39. Yang SS, Liu YB, Yu JB, Fan Y, Tang SY, Duan WT, Wang Z, Gan RT and Yu B: Rapamycin protects heart from ischemia/reperfusion injury independent of autophagy by activating PI3 kinase-Akt pathway and mitochondria K(ATP) channel. Pharmazie 65: 760-765, 2010.

This work is licensed under a Creative Commons Attribution-NonCommercial-NoDerivatives 4.0 International (CC BY-NC-ND 4.0) License. 